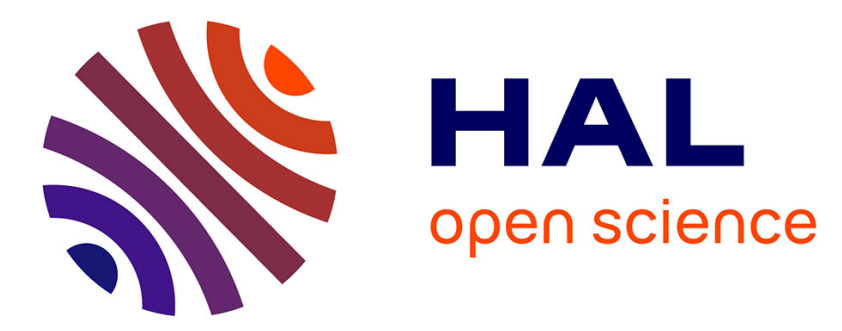

\title{
InAlN - A New Barrier Material for GaN-Based HEMTs
} Erhard Kohn, F Medjdoub

\section{To cite this version:}

Erhard Kohn, F Medjdoub. InAlN - A New Barrier Material for GaN-Based HEMTs. International Workshop on The Physics of Semiconductor Devices, Dec 2007, Bombay, India. hal-03281342

\section{HAL Id: hal-03281342 https://hal.science/hal-03281342}

Submitted on 8 Jul 2021

HAL is a multi-disciplinary open access archive for the deposit and dissemination of scientific research documents, whether they are published or not. The documents may come from teaching and research institutions in France or abroad, or from public or private research centers.
L'archive ouverte pluridisciplinaire HAL, est destinée au dépôt et à la diffusion de documents scientifiques de niveau recherche, publiés ou non, émanant des établissements d'enseignement et de recherche français ou étrangers, des laboratoires publics ou privés. 


\title{
InAlN - A New Barrier Material for GaN-Based HEMTs
}

\author{
Erhard Kohn and Farid Medjdoub
}

\begin{abstract}
The InAIN/GaN heterojunction is a new alternative to the common $\mathrm{AlGaN} / \mathrm{GaN}$ configuration with high sheet charge density and high thermal stability, promising very high power and temperature performance as well as robustness. The status, focussing on the lattice matched materials configuration is reviewed.
\end{abstract}

Index Terms - High temperature electronics, high power devices, III-nitrides, InAIN/GaN heterostructure.

\section{INTRODUCTION}

The $\mathrm{AlGaN} / \mathrm{GaN}$ materials system has been the workhorse for more than 10 years for GaN-based heterostructure FETs, setting records for high power microwave performance. The main advantages of this structure have been the wide bandgap and a high polarization induced 2DEG-channel charge density. Two polarization effects contribute. These are the difference in spontaneous polarization of $\mathrm{GaN}$ and $\mathrm{AlGaN}$ respectively and the piezopolarization induced by the strain of the lattice mismatched heterostructure. At $30 \% \mathrm{Al}$-content the two contributions are roughly equal. An alternative to the $\mathrm{AlGaN} / \mathrm{GaN}$ heterostructure can be InAlN/GaN, but what is the advantage when substituting a proven concept?

Four aspects have been especially important for the very high power operation of $\mathrm{AlGaN} / \mathrm{GaN}$ heterostructure FETs: a high sheet charge density in combination with a high breakdown field, an efficient heat dissipation when using $\mathrm{SiC}$ substrates, the control of surface related instabilities and the chemical and thermal stability of the heterostructure and its surface. In the following it will be shown that these features can still be improved further by substituting the AlGaN barrier by InAlN.

As can be seen from the composition diagram of the III-nitride materials matrix (fig. 1), InAlN can be grown lattice matched to GaN. Thus, at this composition stress and piezopolarisation are absent, potentially improving the stability of the heterostructure.

Even without piezopolarisation, the 2DEG-channel

Manuscript received September 31, 2007 The work was supported in part by the European Union within the framework FP6 (ULTRAGaN).

Both authors are with the Inst of Electron Devices and Circuits, University of Ulm, 89081Ulm, Germany

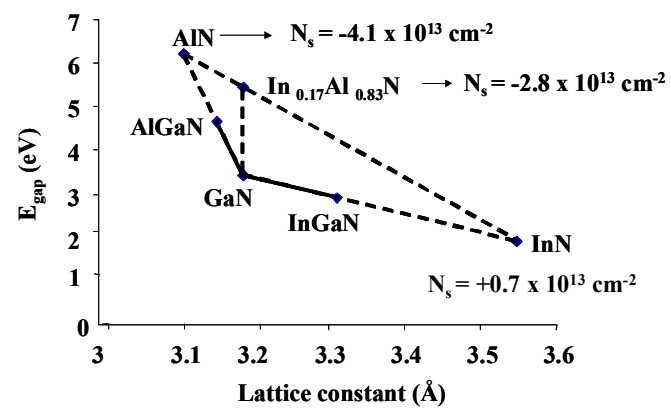

Fig. 1: GaN-based heterostructure materials matrix and polarization induced interface charge densities on GaN substrate

sheet charge density induced by the difference in spontaneous polarisation is larger than typically in the $\mathrm{AlGaN} / \mathrm{GaN}$ heterostructure. This should result in a higher output current density and, if the breakdown conditions can be preserved, even higher power density. The high Al-content places the InAlN alloy closer to AlN than the AlGaN alloy used in AlGaN/GaN FETs. AlN possesses the highest spontaneous polarisation in the materials matrix and a Curie temperature well above $1000{ }^{\circ} \mathrm{C}$, indicating a high chemical/thermal stability. In comparison, $\mathrm{GaN}$ decomposes in atmosphere at $650{ }^{\circ} \mathrm{C}$ [1], although grown mostly at around $1000{ }^{\circ} \mathrm{C}$. Thus, InAlN/GaN heterostructure FETs may display a higher chemical/thermal stability than their $\mathrm{AlGaN} / \mathrm{GaN}$ counterparts potentially allowing operation at higher temperature and improving robustness. A high chemical stability may also result in an improved control of the surface instabilities, plaguing polarization dipole induced channels. At the same time it may also allow to implement thinner barriers. In the following these characteristics will be discussed to see, whether the above mentioned improvements can indeed be expected.

\section{HETEROJUNCTION MATERIAL PROPERTIES}

Of interest to microwave power devices are InAlN barrier compositions with high Al-content, in between the lattice matched composition with an interfacial $2 \mathrm{DEG}$ density of $2.8 \times 10^{13} \mathrm{~cm}^{-2}$ only generated by the discontinuity in spontaneous polarization and AIN with the highest channel sheet charge density of $4.1 \times 10^{13} \mathrm{~cm}^{-}$ ${ }^{2}$ in the entire GaN-based materials matrix. To obtain a high 2DEG carrier mobility, a thin AlN smoothing layer needs to be inserted like in the case of the $\mathrm{AlGaN} / \mathrm{GaN}$ heterostructure [2]. Thus, also the lattice matched configuration will contain a thin strained layer. With 
increasing Al-content the barrier becomes increasingly stressed, resulting in a critical thickness of only a few $\mathrm{nm}$ for AlN. Barrier layers with high Al-content are therefore thin and barrier and AIN smoothing layers need to be considered as a common system.

AlN is an extremely stable electroceramic with a phase stability and Curie temperature above $2200{ }^{\circ} \mathrm{C}$, depending on the materials quality. Single crystal substrates have been shown to be highly insulating up to at least $1000{ }^{\circ} \mathrm{C}$ in vacuum even without oxygen compensation [3]. On the other hand, $\mathrm{GaN}$ will decompose in atmosphere at $650{ }^{\circ} \mathrm{C}$ as mentioned above. It may be expected that the $\mathrm{AlGaN} / \mathrm{GaN}$ and InAlN/GaN heterostructures display a thermal stability limit between that of the two binaries. AlGaN/GaN HEMT devices could be operated for a short period of time up to around $750{ }^{\circ} \mathrm{C}$, depending on the crystalline quality of the heterojunction [4]. From reliability investigations [5] it may be speculated that degradation may be triggered by the built-in stress of the heterojunction (usually with a barrier of approx. $30 \% \mathrm{Al}$-content and $25 \mathrm{~nm}$ thickness). In the case of InAlN barriers high thermal stability above $900{ }^{\circ} \mathrm{C}$ has been found for the lattice matched configuration, however reduced when strained [6]. This may lead to the following picture: The GaN heteromaterial system contains usually still a high density of mostly vertically oriented defects. If the barrier layer contains Ga this will provide vertical Ga-related diffusion paths especially along strain related defects and the thermal stability is higher than that of GaN depending on the materials quality. It will improve further, if passivated against atmosphere for example by a $\mathrm{Si}_{3} \mathrm{~N}_{4}$ cap. On the other hand, the lattice matched InAlN/GaN heterojunction does not contain Ga-related diffusion paths and is stress balanced. In essence a defect free structure without AIN interlayer may be viewed against its ultimate limit, given by its phase stability.

An important aspect of the heterojunction, when applied to FET devices, is its surface. The III-nitrides are highly polar, and the polarization countercharge of the 2DEG channel is found on the surface, if the barrier layer is undoped. It may be located in a surface donor level [7], in trap levels within the dielectric passivation or on the surface of the passivation layer in electronic states or ionic adsorbates. Clearly for high electronic stability deep surface trapping centres should be avoided. It may therefore also be helpful to compare the electrochemical stability, corrosion resistance and electronic surface properties of the two cases. In the case of AlGaN (with $30 \%$ Al-content) a surface donor level of high density is found at around $1.5 \mathrm{eV}$ below the conduction band [7] pinning the surface potential and causing severe DC current and RF power instabilities. Due to this deep level the full interfacial 2DEG density $\left(\sim 10^{13} \mathrm{~cm}^{-2}\right)$ becomes depleted for barrier thicknesses below approx. $25 \mathrm{~nm}$, reducing the maximum accessible drain current density. This trap level can be widely removed by passivation [8] and thinner barriers become possible, but are not widely implemented. In the case of InAlN the surface potential of as-grown heterostructures is pinned at a level of approx. $0.4 \mathrm{eV}$ and the barrier layer thickness can be scaled below $25 \mathrm{~nm}$, enabling planar high aspect ratio devices with $\mathrm{nm}$ gatelength. This is discussed in the following paragraph.

After processing the surfaces are oxygen terminated. Attached to the surface oxygen bonds are in most cases hydroxyl groups. These are electrochemically highly active (especially when in contact with the liquid), the activity stemming from a surface redox potential (or surface state) within the bandgap. In an aqueous electrolyte both compounds can be oxidized further under anodic potential, meaning an oxide film is grown anodically and the surface may corrode. This is in general true for all semiconductor materials, except for diamond, where the surface cannot be oxidized beyond the surface layer; and therefore only diamond can be used as inert electrochemical semiconductor electrode. The behavior under high anodic overpotentials may be illustrated with fig. 2.

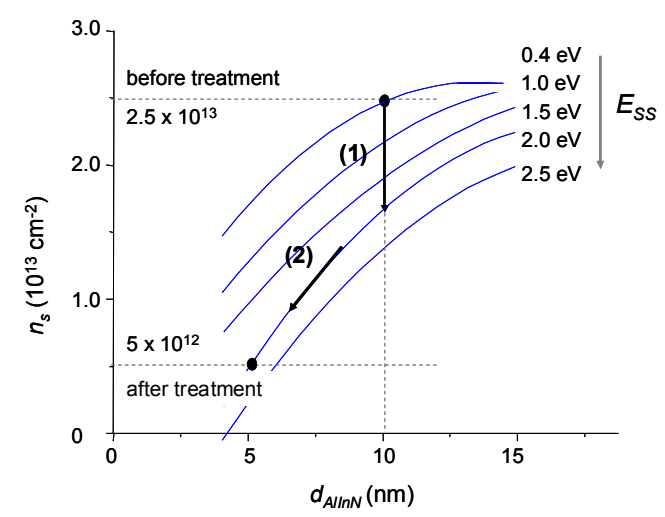

Fig. 2: Dependence of sheet charge density $\mathrm{n}_{\mathrm{s}}$ on barrier layer thickness $d_{\text {AlInN }}$ and surface energy level $E_{\text {ss }}$ with anodic treatment $\mathrm{E}_{\mathrm{ss}}$. The arrows show a suggested path for the anodic oxidation treatment with (1) indicating the change in $\mathrm{E}_{\mathrm{ss}}$ and with (2) indicating the change in $d_{A I I n N}$ due to oxidation. After [9].

In the corresponding experiment [9] the FET structure had been operated in the liquid (in the ISFET mode), where the barrier layer had been in direct contact with the electrolyte in the gate area. Shown is the change of the sheet charge density with oxidation treatment, whereby the level had been related to the heterostructure configuration and here especially the barrier layer thickness of $10 \mathrm{~nm}$ and the surface potential of the electrochemical gate electrode. Indeed, the initial value of $\mathrm{N}_{\mathrm{s}}=2.5 \times 10^{13} \mathrm{~cm}^{-2}$ can be well fitted to a surface potential of approx. $0.4 \mathrm{eV}$. After oxidation the sheet charge density is reduced to $\mathrm{N}_{\mathrm{s}}=5 \times 10^{12} \mathrm{~cm}^{-2}$. This reduction can only be explained taking into account both a change in InAIN barrier thickness (and related oxide formation) and a change of surface potential deep into the bandgap.

In essence, both surfaces are prone to oxidation and corrosion, which may also be associated with a high 
density of dangling bonds and ionic charges (like $\mathrm{OH}^{-}$). Thus, such films need annealing and their surface will need capping and passivation for stable high power and high temperature operation.

\section{DEVICE TECHNOLOGY ASPECTS}

The device technology of GaN-based FET devices follows many common processing steps.

For ohmic contacts $\mathrm{Ti} / \mathrm{Al} / \mathrm{Ni} / \mathrm{Au}$ is mostly used. However, InAIN is a very stable refractory compound and will not produce deep alloying profiles during contact annealing at around $850{ }^{\circ} \mathrm{C}$. The interfacial 2DEG channel needs therefore to be contacted directly by tunnelling and the metallization may need to be placed into a recess trench. Thus, many of the early FET output characteristics show slightly rectifying behaviour. However, the low surface potential of InAlN allows to design barrier layers, which approach the tunnelling thickness, which then allows planar ohmic contact formation and low contact resistances down to $0.35 \Omega$ $\mathrm{mm}$, but will also result in Schottky contacts with high leakage. In this case a dielectric assisted barrier is needed, leading to a MOSFET-like configuration. Fig. 3 shows the improvement in gate leakage when inserting a $5 \mathrm{~nm} \mathrm{Al} \mathrm{O}_{3}$ gate dielectric into a MESFET with $13 \mathrm{~nm}$ InAlN barrier [10]. High-k dielectrics are of special interest like $\mathrm{Al}_{2} \mathrm{O}_{3}$ and $\mathrm{HfO}_{2}$.

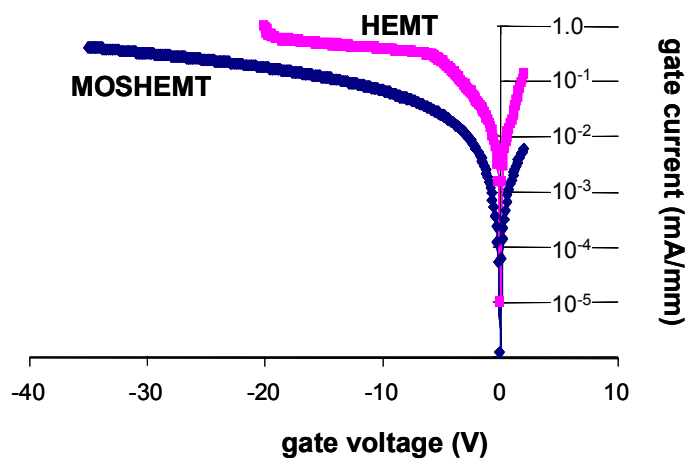

Fig. 3: Gate leakage of $\mathrm{Ni} / \mathrm{Au}$ Schottky contacts of InAlN/GaN HEMTs with $13 \mathrm{~nm}$ barrier and with insertion of $5 \mathrm{~nm} \mathrm{Al}_{2} \mathrm{O}_{3}$ as MOSHEMT

\section{DEVICE PERFORMANCE}

Of prime interest are the high levels in current density, which can be expected for the high interfacial sheet charge density. In combination with a low surface potential this should allow aggressive scaling to obtain semi-enhancement devices with high open channel current density and transconductance. These properties should then also be favourable to obtain high speed performance due to low parasitics. Finally, the high chemical stability of the lattice strained structure may allow to demonstrate high temperature operation in a temperature regime not accessible to FETs before. This will be discussed in the paragraph below.

\section{A. Current density and scaling}

Fig. 4 shows a typical output characteristic of a lattice matched InAlN/GaN HEMT on sapphire with $13 \mathrm{~nm}$ barrier and $0.25 \mu \mathrm{m}$ gatelength. The maximum open channel current is approx. $2.4 \mathrm{~A} / \mathrm{mm}$, which is about twice as much as obtained for $\mathrm{AlGaN} / \mathrm{GaN}$ FETs. This current level is obtained despite the low thermal conductivity of the $\mathrm{Al}_{2} \mathrm{O}_{3}$ substrate and self-heating limits this performance to short gate widths.

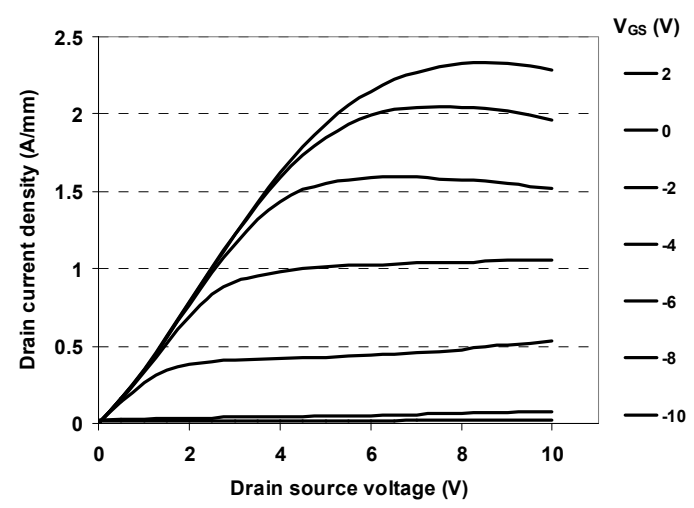

Fig. 4: Output characteristics of lattice matched InAlN/GaN HEMT with $13 \mathrm{~nm}$ barrier grown on sapphire. Gatelength was $0.25 \mu \mathrm{m}$ and gatewidth $25 \mu \mathrm{m}$. After [11].

Under pulse condition self heating is reduced and the maximum output current increased further. This is shown in fig. 5 (after [11]). The saturated current level at $\mathrm{V}_{\mathrm{G}}=$ $+2 \mathrm{~V}$ is already close to the predicted one [12].

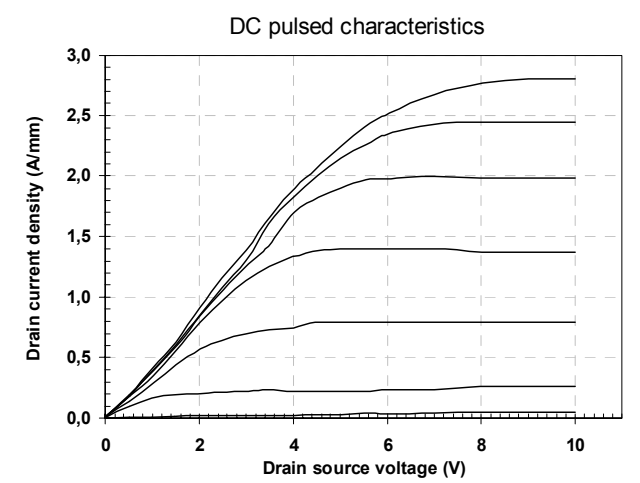

Fig. 5: Pulsed HEMT output characteristics of lattice matched device on sapphire as shown in fig. 4. After [11]

Immersed into liquid nitrogen the maximum open channel current is increased to $3.05 \mathrm{~A} / \mathrm{mm}$. Associated Hall measurements in liquid nitrogen have resulted in an $\mathrm{N}_{\mathrm{s}}=2.6 \times 10^{13} \mathrm{~cm}^{-2}$ and a mobility of $\mu_{\mathrm{n}}=3100 \mathrm{~cm}^{2} / \mathrm{Vs}$.

The low surface potential allows down scaling of the barrier layer to the tunnelling limit and semienhancement mode of operation. Fig. 6 shows the output characteristics of devices with a gatelength of $0.25 \mu \mathrm{m}$, fabricated on lattice matched heterostructures with $8 \mathrm{~nm}$ and $5 \mathrm{~nm}$ barrier layers respectively (adding a $1.0 \mathrm{~nm}$ AlN smoothing layer). As can be seen the maximum open channel current density (at $\mathrm{V}_{\mathrm{G}}=+2 \mathrm{~V}$ ) is slowly 
decreasing to $1.9 \mathrm{~A} / \mathrm{mm}$ and $1.3 \mathrm{~A} / \mathrm{mm}$, in agreement with what can be expected from fig. 2 .
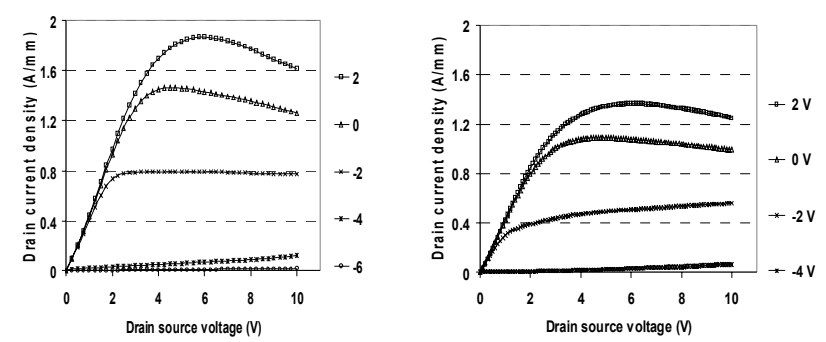

Fig. 6: Output characteristics of lattice matched HEMT structures of identical geometry and two different InAlN barrier thicknesses of $8 \mathrm{~nm}$ (left) and $5 \mathrm{~nm}$ (right). Also included is a $1 \mathrm{~nm}$ AlN smoothing layer. This may also be compared to the characteristics for a barrier of $13 \mathrm{~nm}$ shown in fig. 4. After [10].

The influence of the barrier thickness is also noticeable by the changes in threshold voltage and transconductance as can be seen in figs. 7 and 8 . Fig. 7 shows the dependence of the threshold voltage on the total barrier layer thickness.

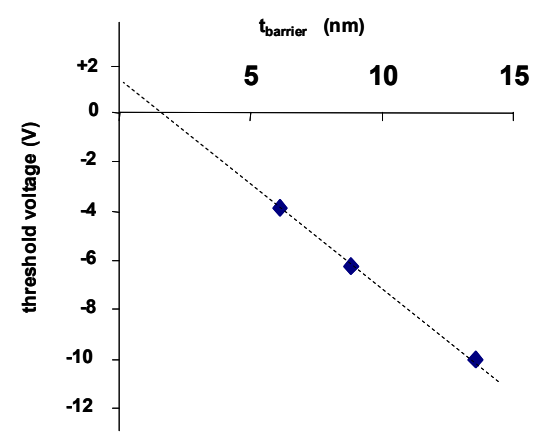

Fig. 7: Threshold voltage dependence on barrier layer thickness of lattice matched HEMTs.

As can be seen, the scaling of the threshold voltage is indeed invers to the total barrier thickness. Enhancement mode of operation is predicted for a barrier thickness of approx. $2 \mathrm{~nm}$, which would then be in combination with an extremely high channel sheet charge and maximum open channel current density. Enhancement mode of operation might be possible up to a gate barrier height of $1.7 \mathrm{~V}$. However, such thin barriers have not been tested up to now. With thinner barrier also the peak transconductance is increased as shown by the transfer characteristics in fig. 8. For the $5 \mathrm{~nm}$ barrier a peak transconductance of $505 \mathrm{mS} / \mathrm{mm}$ is obtained near $\mathrm{V}_{\mathrm{G}}=0$ $\mathrm{V}\left(\mathrm{L}_{\mathrm{g}}=0.25 \mu \mathrm{m}\right)$. Extrapolating, a peak transconductance above $1 \mathrm{~S} / \mathrm{mm}$ may be expected for semi-enhancement devices. However, to draw advantage of the total built-in sheet charge density at low threshold voltage, the depletion caused by the residual surface potential of 0.4 $\mathrm{eV}$ (which acts also as parasitic current limiter) would however still need to be overcome by a recess configuration.

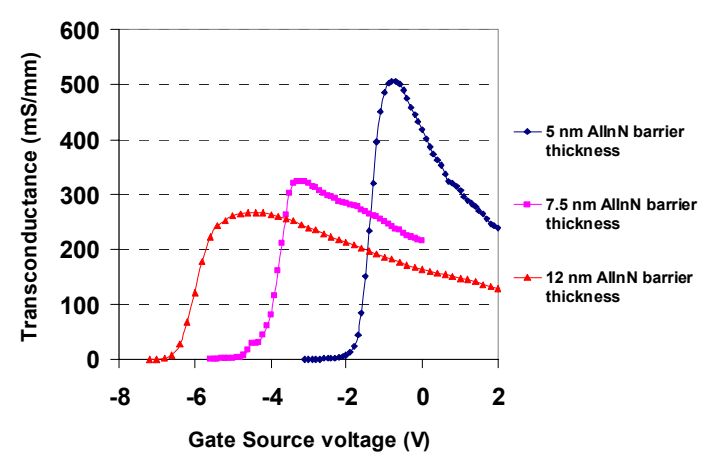

Fig. 8: Dependence of extrinsic transfer characteristics on with barrier layer thickness of lattice matched InAlN/GaN HEMTs with $0.25 \mu \mathrm{m}$ gatelength. After [11].

\section{B. High temperature performance}

The short time temperature stability of InAlN/GaN HEMT structures under DC operation has been tested in vacuum in a temperature ramping experiment. Here the temperature was ramped in $100{ }^{\circ} \mathrm{C}$ steps with a time interval of $30 \mathrm{~min}$ at each temperature, where the DC output characteristics were taken with tungsten carbide test needles in the vacuum chamber [11]. The temperature had been calibrated by several methods (thermocouple reading, pyrometer and melting point detection). At very high temperature, where the thermal losses are the highest, the temperature of the chip surface has been calibrated by melting of the $\mathrm{Au}$ contact metallization at $1063{ }^{\circ} \mathrm{C}$. This was then compared to the thermocouple reading located within the substrate holder. Fig. 9 shows the device under test at $1000^{\circ} \mathrm{C}$.

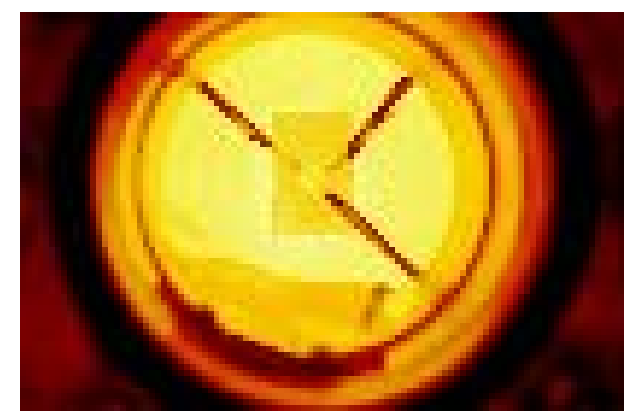

Fig. 9: HEMT device under test at $1000{ }^{\circ} \mathrm{C}$ in vacuum chamber. After [11].

Fig. 10 shows the output characteristic under open channel condition at $\mathrm{V}_{\mathrm{G}}=+2 \mathrm{~V}$ and pinch off at $\mathrm{V}_{\mathrm{G}}=-8$ $\mathrm{V}$ for $300^{\circ} \mathrm{C}, 600^{\circ} \mathrm{C}$ and $800^{\circ} \mathrm{C}$ operation.

It can be seen that ohmic and Schottky contacts are both highly stable. Schottky diode leakage does not prevent transistor action even at $1000{ }^{\circ} \mathrm{C}$ [11]. In the linear region, the channel resistance is gradually increasing, indicating a reduction of mobility with temperature. Up to $600{ }^{\circ} \mathrm{C}$ residual barrier characteristics are still visible in the source and drain contacts, which are overcome only at the highest operating temperature of $800{ }^{\circ} \mathrm{C}$. Up to $600{ }^{\circ} \mathrm{C}$ the maximum output current is also only slightly reduced, indicating that operation up to this 
temperature may still be velocity saturation dominated. At $800^{\circ} \mathrm{C}$ pinch-off is softened. Indeed operation at 1000 ${ }^{\circ} \mathrm{C}$ shows severe bypass conduction through the buffer layer. It seems therefore that the high speed performance at high temperature is influenced by two major factors. The reduction in mobility, so that velocity saturation will only dominate at reduced gatelength; and secondly buffer layer leakage through trap activation resulting in a low output resistance. Especially the second effect will effectively limit the microwave performance of the device severely. It is therefore a challenge to develop $\mathrm{GaN}$ buffer layer configurations, which remain semiinsulating at these high temperatures.

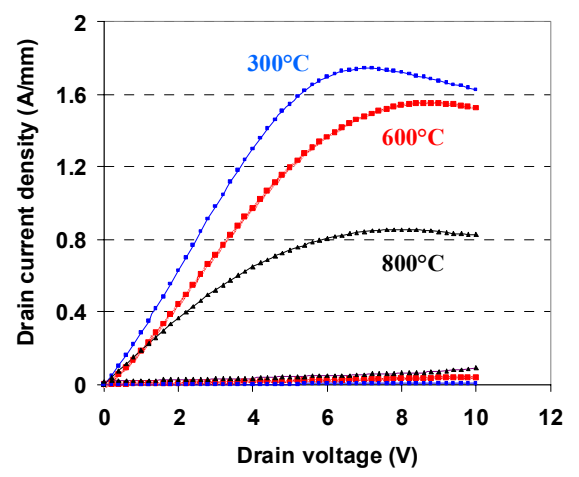

Fig. 10: Output characteristics of $0.25 \mathrm{~mm}$ gatelength devices for $\mathrm{V}_{\mathrm{G}}=$ $+2 \mathrm{~V}$ (open channel) and $\mathrm{V}_{\mathrm{G}}=-8 \mathrm{~V}$ (pinch-off) at $300{ }^{\circ} \mathrm{C}, 600{ }^{\circ} \mathrm{C}$ and $800{ }^{\circ} \mathrm{C}$.

The device characteristics had also been taken after the high temperature cycling experiment and the characteristics compared to the room temperature ones taken before the test. This is shown in fig. 11. As can be seen, the ohmic contacts remain still slightly rectifying. Thus, they have not alloyed in further and the linear characteristics seen in the $800{ }^{\circ} \mathrm{C}$ operation is due to a thermal activation effect. Also, the Ni Schottky contacts have not sintered into the material and the pinch-off voltage remained unchanged. Even the buffer layer current injection behaviour as seen from the $-6 \mathrm{~V}$ gate bias trace remains unchanged. The maximum open channel current is only slightly reduced. In this contest it may also be worth mentioning that the device was still unpassivated. This indicates that even during this rather harsh test the surface potential remained stable and barrier layer oxidation or even corrosion are not noticeable. Thus, despite the fact that InAlN can be anodically oxidized at high overpotentials in an electrolyte, in atmosphere at room temperature and vacuum at high temperature the surface is chemically highly stable.

No indication could be found that the polarization fields in the two materials become unstable or that the heterojunction degrades and that the 2DEG density suffers as a consequence. This is in contrast to the AlGaN/GaN heterojunction, where contacts have also been stable up to the highest temperature of operation $\left(800{ }^{\circ} \mathrm{C}[4]\right)$ but the $2 \mathrm{DEG}$ density and maximum channel current density started to degrade first. In the lattice matched configuration only the $1 \mathrm{~nm}$ AlN interfacial smoothing layer is strained, but sandwiched between the lattice matched barrier and the buffer.
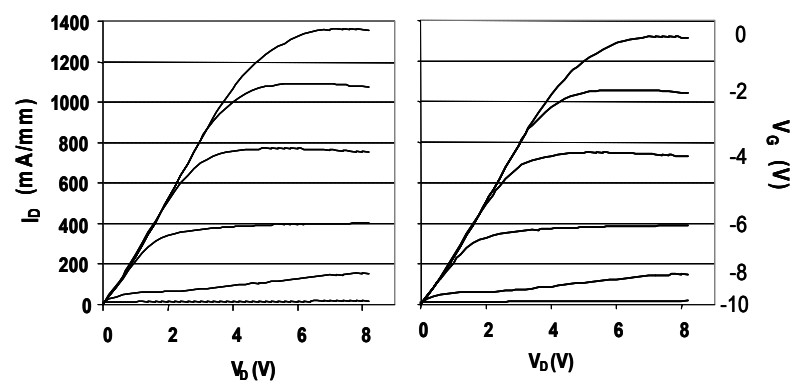

Fig. 11: Output characteristics of the HEMT device shown in fig. 10 before and after the temperature cycling test.

\section{Dynamic characteristics}

The 2DEG mobility at the interface between the GaN buffer and the AlN smoothing layer is still slightly lower than in the case of $\mathrm{AlGaN} / \mathrm{GaN}$ heterojunctions as already mentioned. On the other hand high aspect ratios can be obtained because of thin barrier layers. The small signal microwave performance of InAlN/GaN HEMTs is therefore very comparable with that of $\mathrm{AlGaN} / \mathrm{GaN}$ HEMTs at comparable gatelength with an $\mathrm{f}_{\mathrm{T}}=31 \mathrm{GHz}$ and $\mathrm{f}_{\max }=52 \mathrm{GHz}$ for $0.25 \mu \mathrm{m}$ gatelength (and no $\mathrm{T}$ gate) [13]. The same holds for the small signal performance for MOSHEMTs with a high-k gate dielectric like $\mathrm{Al}_{2} \mathrm{O}_{3}$ [13].

Like in the case of the AlGaN/GaN HEMT structure the large signal performance is largely affected by the polarization dipole character and surface related instabilities like current compression or power slump, when the buffer layer is stable. Many of the phenomena can be associated with surface charging effects between gate and drain commonly dubbed "virtual gate" effect [14]. Here the origin of the instability is seen in the charging and discharging dynamics of the deep surface donor. In part, the charging path may be via generation/recombination in the barrier layer or via lateral surface leakage. This surface leakage may be strongly (gate to drain) field dependent and appears often as lateral charge injection from the gate metal contact into the adjacent surface of the drift region. Both effects are usually identified by pulsing the gate or drain bias respectively. Gate pulsing will therefore be mostly sensitive to traps in the barrier and buffer layer; drain bias pulsing will be especially sensitive to surface effects. At high drain bias high fields develop in the gate-drain drift region and there may be a threshold, when lateral surface charge injection and "drain-lagging" appears. It should be remembered that a polarization dipole charge density of nearly $3 \times 10^{13} \mathrm{~cm}^{-2}$ is acting on the surface as the channel counter charge, which amounts to approx. $1 \%$ of the total surface atom density. The low surface potential of unpassivated devices indicates that the surface donor 
trapping characteristics may be fast and surface related dispersion may be in the $\mathrm{MHz}$ range. In addition, the high density may enable hopping conduction along the surface. Clearly for stable operation the InAlN surface needs to be characterized further and a clean interface to a wide bandgap high-k dielectric overlayer developed.

Pulse experiments reveal up to now the same characteristics as seen in AlGaN/GaN HEMTs and depend essentially on the passivation technology used. Behaviour with low dispersion has been seen, but has not yet been verified in power experiments [15]. Microwave power measurements have still shown conservative results [16].

\section{OUTLOOK AND CONCLUSION}

The InAlN/GaN HEMT technology is still rather immature, although the heterostructure growth techniques by MOCVD and MBE are already quite advanced. High sheet charge densities as expected for ideal polarization properties have been obtained in the lattice matched condition as well as high mobilities at high 2DEG density. Planar structures with high aspect ratio can be realized, so that the advantage of the high sheet charge density is also seen in short channel FETs with $\mathrm{nm}$ gatelength. Thus the system promises very high power densities at high frequency. The stabilization of the surface properties is however still a challenge. Dispersion effects as seen in AlGaN/GaN HEMTs are still present and an efficient surface passivation scheme, which can handle the high power conditions has not been developed yet.

In the lattice matched composition the materials system is chemically extremely stable. This has allowed FET operation at $1000{ }^{\circ} \mathrm{C}$ in vacuum for the first time. In this first short time experiment it could be seen that neither the ohmic contacts, nor the Schottky contacts or the heterostructure itself had degraded. This may eventually translate into high reliability and robustness under very high power operation.

A challenge left for the future is certainly also the development of strained structures of even higher Alcontent in the barrier and eventually an AlN barrier FET. Such structures have been investigated from time to time in the past, but have suffered from the fact that the strain developed in this case limits the barrier layer thickness to only a few nm. However, in the case of InAlN/GaN HEMTs, the barrier thickness could already be reduced to $5 \mathrm{~nm}$. Therefore it seems feasible to meet the technological window for such an ultimate device configuration some time in the future. Indeed, in this case the highest 2DEG channel sheet charge concentration of the III-Nitride system could be used and the power handling capability extended still further.

\section{ACKNOWLEDGMENT}

The work presented has been mainly performed within the frame of the European joint project ULTRAGaN coordinated by S. Delage of Thales-Alcatel. Many thanks are therefore to all members of this consortium at EPFL in Lausanne ( J.-F. Carlin), the University of Vienna (J. Kuzmik), FORTH in Crete (A. Konstantinidis), Aixtron in Aachen (Heuken) and Thales-Alcatel III-V Labs near Paris (M.-A. Poisson). Initial experiments have been undertaken in cooperation with the University of Magdeburg (A. Krost, A. Dadgar) laying the groundwork for this investigation.

\section{REFERENCES}

[1] A. Pisch and R. Schmid-Fetzer, "In situ decomposition study of GaN thin films," J. Cryst. Growth, vol. 187, pp. 329-332, 1998.

[2] M. Gonschorek, J.-F. Carlin, E. Feltin, M. A. Py, and N. Grandjean, "High electron mobility lattice matched AlInN/GaN field-effect transistor heterostructures," Appl. Phys. Lett. 89, 062106, 2006

[3] M. Neuburger, A. Aleksov, R. Schlesser, E. Kohn, Z. Sitar, "Electronic high temperature characteristics of AlN," Electronics Lett., 43 (2007), 592

[4] I. Daumiller, C. Kirchner, M. Kamp; K.J. Ebeling, E. Kohn, "Evaluation of the temperature stability of AlGaN/GaN heterostructure FET's," IEEE Electron Device Lett., Vol. 20, pp. 448, 1999

[5] J. Joh, J.A. Del Alamo, "Mechanisms for Electrical Degradation of GaN High-Electron Mobility Transistors," 2006 Int. Electron Devices Meeting, 2006, Technical Digest, 415

[6] A. Gadanecz, J. Bläsing, A. Dadgar, C. Hums, and A. Krost, "Thermal stability of metal organic vapor phase epitaxy grown AlInN," Appl. Phys. Lett. 90 (2007), 221906

[7] J. P. Ibbetson, P. T. Fini, K. D. Ness, S. P. DenBaars, J. S. Speck, and U. K. Mishra, "Polarization effects, surface states, and the source of electrons in $\mathrm{AlGaN} / \mathrm{GaN}$ heterostructure field effect transistors," Appl. Phys. Lett., 77 (2000), 250-252

[8] B. M. Green, K.K. Chu, E.M. Chumbes, J.A. Smart, J.R. Shealy; L.F. Eastman, "The effect of surface passivation on the microwave characteristics of undoped AlGaN/GaN HEMTs," IEEE Electron Device Lett., 21 (2000), 268

[9] C. Pietzka et al., "Effect of anodic oxidation on the characteristics of lattice matched AlInN/GaN heterostructures in electrolytes," TMS 2007 Electronic Mat. Conf. (EMC), Final Program, p. 29, Abstract A5

[10] F. Medjdoub et al., "Barrier layer downscaling of InAlN/GaN HEMTs," $65^{\text {th }}$ Device Research Conference (DRC), 2007, Tech. Digest, 109

[11] F. Medjdoub et al., "Can InAlN/GaN be an alternative to high power / high temperature AlGaN/GaN devices?," 2006 Int. Electron Devices Meeting (IEDM), 2006, Tech. Digest, 927

[12] J. Kuzmik, "Power electronics on InAlN/(In)GaN: Prospect for a record performance," IEEE Electron Device Lett., 22 (2001), 510

[13] F. Medjdoub et al., "Characteristics of A12O3/AlInN/GaN MOSHEMT," IEE Electronics Lett., 43 (2007), 691

[14] R. Vetury, N.Q. Zhang, S. Keller; U.K. Mishra, "The impact of surface states on the DC and RF characteristics of AlGaN/GaN HFETs," IEEE Trans. Electron Devices, 48 (2001), 560

[15] J. Kuzmik et al., "Gate-lag and drain-lag effects in $(\mathrm{GaN}) / \mathrm{InAlN} / \mathrm{GaN}$ and InAlN/AlN/GaN HEMTs," phys. stat. sol. (a), 204 (2007), 2019-2022

[16] G. H. Jessen et al., "Short-Channel Effect Limitations on HighFrequency Operation of AlGaN/GaN HEMTs for T-Gate Devices," IEEE Electron Device Lett., 28 (2007) 